\title{
ANATOMIA DO LENHO DE CONDALIA BUXIFOLIA REISSEK (RHAMNACEAE)1
}

\author{
TALITA BALDIN ${ }^{2}$ LUCIANO DENARDI $^{3}$ RÔMULO TREVISAN ${ }^{4}$ SILVANA NISGOSKI $^{5}$
}

\section{RESUMO}

São descritos e ilustrados os caracteres microscópicos da madeira de Condalia buxifolia Reissek, arbusto nativo no Estado do Rio Grande do Sul. Foram encontrados poros de diâmetro muito reduzido, em arranjo dendrítico, parênquima paratraqueal escasso e raios heterogêneos. Ressalta-se a presença de fibras de paredes muito espessas que, somado a outras características do lenho, indicam a espécie como uma das madeiras mais pesadas do Rio Grande do Sul.

Palavras-chave: Anatomia da Madeira, Condalia buxifolia, Rhamnaceae.

\section{ABSTRACT}

[Wood anatomy of Condalia buxifolia Reissek (Rhamnaceae)].

The wood microscopic features of Condalia buxifolia Reissek, a native shrub in Rio Grande do Sul State (Brazil), are described and illustrated. Vessels with small diameter, in dendritic pattern, scanty paratracheal axial parenchyma and heterogeneous rays were observed. The abundance of very thick-walled fibres allied with other anatomical features makes the species one of the most weighty woods in Rio Grande do Sul State Flora.

Key words: Condalia buxifolia, Rhamnaceae, Wood Anatomy.

\section{INTRODUÇÃO}

A família Rhamnaceae inclui cerca de 50 gêneros e 900 espécies de árvores, arbustos, lianas e ervas, distribuídas, principalmente, em regiões tropicais do mundo (Judd et al., 2009; Souza \& Lorenzi, 2008). No Brasil, a família

1 Recebido para publicação em 10-09-2011 e aceito para publicação em 01-10-2011.

2 Acadêmica do Curso de Engenharia Florestal do Centro de Educação Superior Norte do Rio Grande do Sul, Universidade Federal de Santa Maria/CESNORS, Frederico Westphalen (RS). taba_m@ @hotmail.com

3 Engenheiro Florestal, Doutor, Professor Adjunto do Departamento de Engenharia Florestal, Universidade Federal de Santa Maria/CESNORS, CEP 98400-000, Frederico Westphalen (RS).

lucianodenardi@yahoo.com.br

4 Engenheiro Florestal, Doutor, Professor Adjunto do Departamento de Engenharia Florestal, Universidade Federal de Santa Maria/CESNORS, CEP 98400-000, Frederico Westphalen (RS). romulo_trevisan@yahoo.com.br

5 Engenheira Florestal, Doutora, Professora Adjunto do Departamento de Engenharia e Tecnologia Florestal, Universidade Federal do Paraná, CEP 80210-170, Curitiba (PR).nisgoski@ufpr.br está representada por 13 gêneros e cerca de 50 espécies, 9 das quais ocorrem naturalmente em áreas campestres, no estrato inferior e orla de florestas, no Estado do Rio Grande do Sul, (Santos et al., 2007A).

Na morfologia das Ramnáceas, destacam-se: folhas simples (alternas ou opostas); flores pouco vistosas, com número de estames igual ao de pétalas; e frutos do tipo drupa, cápsula ou esquizocarpo, raro sâmara (Souza \& Lorenzi, 2008).

As espécies do gênero Condalia foram mais abundantes no passado (cerca de três mil anos), de acordo com diagramas antropológicos do Sudeste do Brasil (Sheel, 2004). O gênero compreeende, atualmente, cerca de 10 espécies de arbustos e raras árvores, de até 10 metros de altura (Record \& Hess 1942).

Condalia buxifolia, conhecida como coronilha-folha-de-buxo, é arbusto nativo no Rio Grande do Sul. Única espécie do gênero, no Estado, habita, sobretudo, em regiões campestres da metade sul, onde é considerada rara (Silva \& Oliveira, 1989). 
Planta espinescente, caducifólia e com entrenós muito curtos, Condalia buxifolia apresenta folhas simples, inteiras, obovadas, discolores (Alonso, 1997), bem como flores reunidas em fascículos e frutos do tipo baga (Lorenzi, 2009). Mesmo sem madeira de valor comercial, a espécie fornece excelente lenha e a planta tem propriedades antifebrífugas, antiinflamatórias e contra disenterias, servindo na medicina popular (Maldaner, 2005).

Para as Ramnáceas, Metcalfe \& Chalk (1972) referem, em outros aspectos: vasos pequenos, por vezes grandes em algumas espécies, comumente em múltiplos e em arranjo tendente a radial; porosidade em anel; placas de perfuração simples; pontoações intervasculares alternas; parênquima predominantemente paratraqueal, vasicêntrico, aliforme ou confluente; raios heterogêneos a homogêneos, com 2 - 5 células de largura; fibras com pontoações simples; e traqueóides vasculares presentes em espécies com vasos em arranjo diagonal ou dendrítico. Os autores destacam, ainda, a presença de células mucilaginosas em espécies de Condalia, de células taniníferas em Condalia, Maesopsis, Pomaderris, Rhamnella e Scutia, e de aglomerados de cristais em Colubrina, Condalia, Krugiodendron e Pomaderris.

Sob o ponto de vista anatômico do lenho, destacam-se-se, ainda, os trabalhos recentes de Santos et al. (2007A,B; 2008) sobre Ramnáceas nativas no Rio Grande do Sul.

$\mathrm{O}$ presente trabalho tem por objetivo descrever e analisar a estrutura anatômica do lenho de Condalia buxifolia Reissek.

\section{MATERIAL E MÉTODOS}

Os exemplares de Condalia buxifolia Reissek selecionados para o presente estudo são procedentes da localidade de Guaritas, município de Caçapava do Sul - RS.

As exsicatas, bem como a amostra de madeira (torete) foram anexadas ao Herbário e Xiloteca do Departamento de Engenharia Florestal (HDEF) da Universidade Federal de San- ta Maria (Campus de Frederico Westphalen), sob o número 302.

$\mathrm{Da}$ amostra de madeira foram confeccionados corpos de prova, orientados para obtenção de cortes nos três planos anatômicos. O preparo de lâminas histológicas seguiu a técnica padrão (Burger \& Richter, 1991): após fervura em água (150 horas), os corpos de prova foram seccionados em micrótomo de deslize. $\mathrm{Na}$ sequência, os cortes foram coloridos com safranina e azul-de-astra, desidratados em série alcoólica, diafanizados com xilol e montados em lâminas permanentes, com "Entellan".

Para a dissociação do tecido lenhoso, utilizou-se o método Ácido Nítrico-Acético (Barrichelo et al., 1983). A solução macerante, contendo 5 partes de ácido acético para 1 de ácido nítrico, foi posteriormente diluída em água destilada, na proporção 2:1. A maceração foi conduzida em banho-maria, sob ebulição, durante 2 horas. Concluída esta etapa, as células foram reunidas em papel filtro, e tingidas com safranina $1 \%$, durante 10 minutos.

A desidratação foi realizada pela adição de álcool comum $\left(90^{\circ}\right)$ e, posteriormente, álcool absoluto, em intervalos de 2 minutos, aproximadamente. Utilizou-se xilol, na diafanização, e montagem permanente, com "Entellan".

A descrição qualitativa do lenho baseou-se nas recomendações do IAWA Committee (1989). A determinação da fração dos diferentes tecidos foi obtida com um contador de células, segundo a metodologia proposta por Marchiori (1980).

Todas as medições e contagens foram feitas em microscópio LEICA DM 1000, com ocular graduada, no Laboratório de Anatomia da Madeira da UFSM/CESNORS. As fotomicrografias da madeira foram obtidas em microscópio Olympus CX-40, no Laboratório de Anatomia da Madeira da Universidade Federal do Paraná.

No texto descritivo da madeira, os valores referentes a determinadas características anatômicas são apresentados da seguinte forma: $\mathrm{x} \pm \mathrm{s}$ (valor mínimo - valor máximo), onde: $\mathrm{x}=$ média; $\mathrm{s}=$ desvio padrão. 


\section{DESCRIÇÃO ANATÔMICA}

Anéis de crescimento marcados por acentuado contraste na espessura da parede de fibras, entre os lenhos inicial e tardio. A nítida delimitação dos anéis resulta tanto do achatamento radial das fibras, ao final do lenho tardio, como do maior diâmetro dos vasos, no início do anel seguinte (Figura 1A,B).

Vasos: arredondados, muito pequenos (Figura 1C), de $24 \pm 8,3(8-40) \mu \mathrm{m}$ de diâmetro, em distribuição semi-difusa e arranjo dendrítico (Figura 1A,B), compondo 17\% do volume da madeira. Elementos vasculares de $248 \pm 27,1$ (200 - 320) $\mu \mathrm{m}$ de comprimento, com apêndices curtos até longos (cerca de 1/3 do comprimento total do vaso), em uma ou em ambas as extremidades. Espessamentos helicoidais, presentes. Placas de perfuração simples, oblíquas (Figura 1E). Tiloses e depósitos, ausentes. Pontoações intervasculares alternas, arredondadas $(6 \pm 1,2(4-8) \mu \mathrm{m})$, com abertura elíptica, inclusa, horizontal ou obliqua. Pontoações parênquimo-vasculares e raio-vasculares, semelhantes às intervasculares.

Parênquima axial: paratraqueal escasso (Figura $1 \mathrm{C}$ ), por vezes com gomo-resina, representando $7 \%$ do volume da madeira. Séries parenquimáticas de $261 \pm 33,6(188-338) \mu \mathrm{m}$ de altura (Figura 1E), com $3-6$ células, e $13 \pm$ $1,9(10-17) \mu \mathrm{m}$ de largura.

Raios: heterogêneos, com células procumbentes, quadradas e curtamente eretas; pontoações simples, conspícuas na parede (Figura 1D,E). Com frequiência de $14 \pm 1,6(11-$ 16) raios $/ \mathrm{mm}$, o tecido radial ocupa $34 \%$ do volume da madeira. Os unisseriados (12\%), normalmente com $5 \pm 2,3(1-11)$ células quadradas e/ou eretas (Figura 1F), de 83 $\pm 34,9$ (11 - 183) $\mu \mathrm{m}$ de altura e $11 \pm 3(6-19) \mu \mathrm{m}$ de largura. Os multisseriados, predominantemente tetrasseriados $(37 \%)$, menos comumente trisseriados (30\%) e bisseriados (21\%), reúnem células procumbentes, no centro, e $1-2$ fileiras de células quadradas e eretas (ou somente eretas), nas margens (Figura 1F); de $318 \pm 112,7$
$(115-513) \mu \mathrm{m}$ de altura, com $20 \pm 7,9(6-35)$ células, e $33 \pm 6,9(16-46) \mu \mathrm{m}$ de largura. Raios agregados e fusionados, freqüentes.

Fibras: libriformes, não-septadas (Figura 1E), compondo $42 \%$ do volume da madeira; muito curtas $(785 \pm 102,5(550-1050) \mu \mathrm{m})$, de paredes muito espessas (Figura 1C) e com pontoações simples (fenda oblíqua), apenas nas faces radiais da parede. Fibras gelatinosas, abundantes, por vezes compondo largas faixas em plano transversal, visivelmente distintas das demais fibras pela coloração. Espessamentos helicoidais, traqueóides vasculares e traqueóides vasicêntricos, ausentes.

Outros caracteres: células de raio com abundante gomo-resina e, por vezes, com cristais prismáticos (normalmente um por célula). Canais intercelulares, tubos laticíferos e taniníferos, floema incluso, células oleíferas, máculas medulares e estratificação, ausentes.

\section{ANÁLISE DA ESTRUTURA ANATÔMICA}

A estrutura anatômica do lenho de Condalia buxifolia concorda, em linhas gerais, com o descrito por Metcalfe \& Chalk (1972) para as Ramnáceas: poros de diâmetro reduzido; placas de perfuração simples; pontoações intervasculares alternas; parênquima paratraqueal; raios heterogêneos com até 4 células de largura, por vezes com cristais prismáticos; e fibras com pontoações simples. Em contraponto, não foram observados traqueóides vasculares, aspecto citado pelos autores acima referidos como freqüente em Ramnáceas com vasos em arranjo dendrítico, bem como células mucilaginosas e taniníferas.

Cabe ressaltar que a madeira de Condalia buxifolia apresenta fibras de paredes muito espessas, por vezes gelatinosas, e lumes praticamente obliterados, bem como vasos muito pequenos (24 $\mu \mathrm{m}$, em média) e parênquima axial escasso. Nem mesmo o lenho de Myracrodruon balansae (pau-ferro), uma das madeiras mais pesadas do Rio Grande do Sul (1,17 - 1,25 g/ $\mathrm{cm}^{3}$ ), segundo Tortorelli (2009) e Lorenzi 

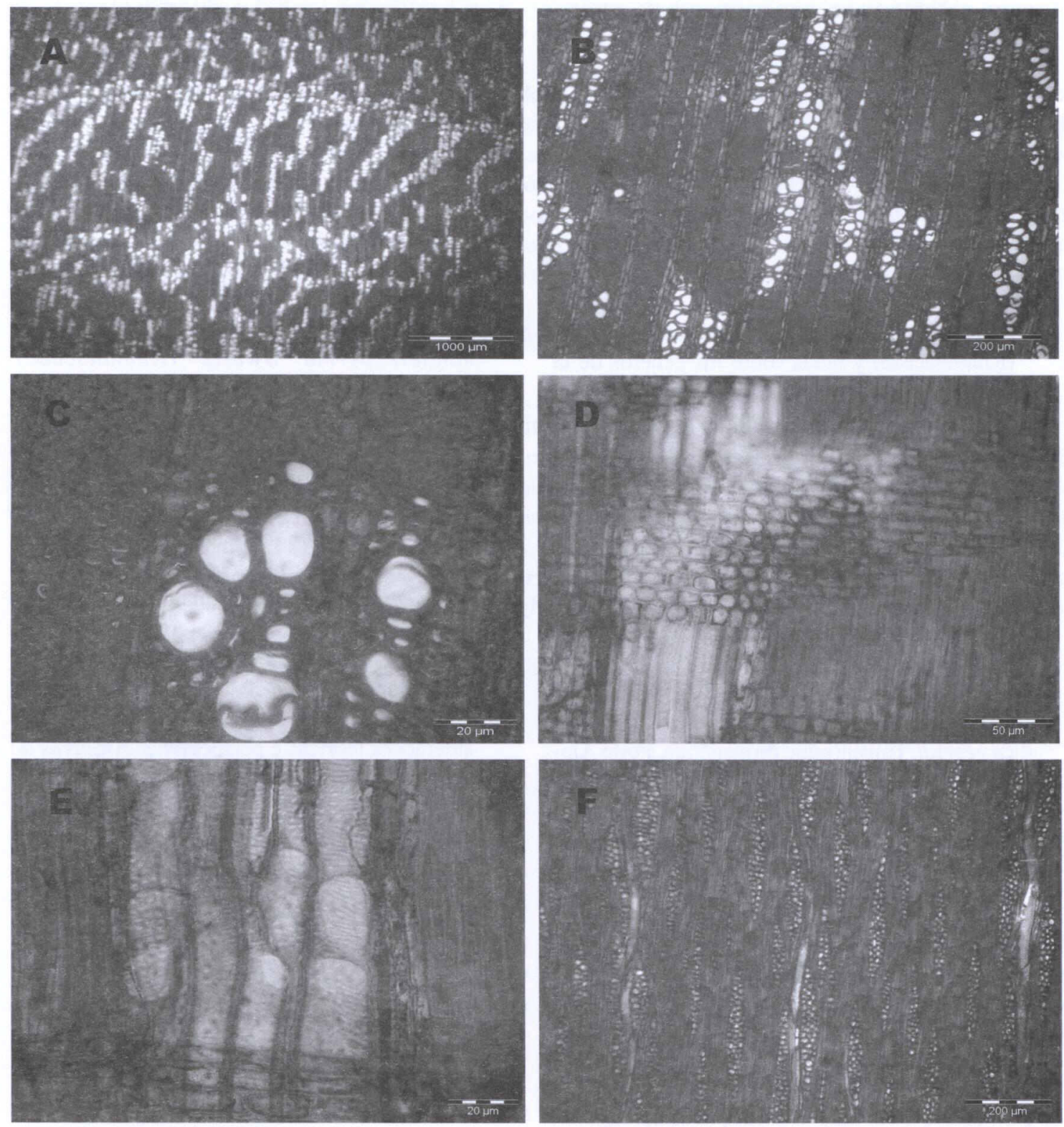

FIGURA 1 - Fotomicrografias da madeira de Condalia buxifolia Reissek. A - Anel de crescimento e vasos arredondados, em distribuição semi-difusa e arranjo dendrítico (seção transversal). B - Mesma seção, com maior aumento, mostrando vasos de maior diâmetro no lenho inicial. C - Fibras de paredes muito espessas e parênquima paratraqueal escasso (seção transversal). D - Aspecto geral de raio heterogêneo (seção longitudinal radial). E - Placas de perfuração simples, espessamentos espiralados e séries de parênquima axial (seção longitudinal radial). F-Raios uni e multisseriados, com até 4 células de largura (seção longitudinal tangencial). 
(2009), exibe caracteres anatômicos tão evidentes de elevada massa específica.

Tal inferência explica o elevado tempo de fervura necessário ao amolecimento da madeira, com vistas à microtomia, embora nem sempre a relação entre massa específica da madeira e tempo de fervura seja linear. A estrutura anatômica, em outras palavras, indica que Condalia buxifolia é uma das madeiras mais pesadas do Rio Grande do Sul.

\section{REFERÊNCIAS BIBLIOGRÁFICAS}

ALONSO, J.F. Nueva especie de Condalia Cav. (Rhamnaceae) y notas sobre los géneros de la familia en la flora de Colombia. Caldasia, Colombia, v. 19, n. 1-2, 1997.

BARRICHELO, L.E.G.; FOELKEL, C.E.B. Processo nítrico-acético para maceração de madeira. Silvicultura, n. 28, p. 732-733, 1983.

BURGER, L.M.; RICHTER, H.G. Anatomia da Madeira. São Paulo: Nobel, 1991. 154 p.

IAWA COMMITTEE. IAWA list of microscopic features for hardwood identificacion. IAWA Bulletin, v. 10, n. 3, p. 218-359, 1989.

JUDD, W.S.; CAMPBELL, C.S.; KELLOGG, E.A.; STEVENS, P.F.; DONOGHUE, M.J. Sistemática vegetal: Um enfoque filogenético. Porto Alegre: Artmed, 2009. p. 471 - 475.

LORENZI, H. Árvores brasileiras: Manual de identificação e cultivo de plantas arbóreas nativas do Brasil. Nova Odessa: Instituto Plantarum, 2009. $384 \mathrm{p}$.

MALDANER, G. Estudo dos metabólitos secundários de Condalia buxifolia e Scutia buxifolia e suas atividades antimicrobianas. Santa Maria: Universidade Federal de Santa Maria, 2005. 96 f. Dissertação (Mestrado em Química - UFSM).

MARCHIORI, J.N.C. Estudo anatômico do xilema secundário de algumas espécies dos gêneros Acacia e Mimosa, nativas no estado do Rio Grande do Sul. Curitiba: Universidade Federal do Paraná, 1980. 186 f. Dissertação (Mestrado em Engenharia Florestal - UFPR).

METCALFE, C.R.; CHALK, L. Anatomy of the Dicotyledons. Oxford: Clarendon Press, 1972. $1500 \mathrm{p}$.

RECORD, S.J.; HESS, R.W. Timbers of the New World. New Haven: Yale University Press, 1942. $640 \mathrm{p}$.

SANTOS, S.R.; MARCHIORI, J.N.C.; CANTODOROW, T.S. Identificação botânica e anatomia da madeira de Discaria americana Gillies et Hooker. Balduinia, n.10, p. 11-20, 2007A.

SANTOS, S.R.; MARCHIORI, J.N.C.; CANTODOROW, T.S.; DENARDI, L. Estudo anatômico do lenho e descrição botânica de Rhamnus sphaerosperma Swartz (Rhamnaceae). Balduinia, n.11, p. 16-26, 2007B.

SANTOS, S.R.; MARCHIORI, J.N.C.; CANTODOROW, T.S. Anatomia da madeira e descrição morfológica de Scutia buxifolia Reissek (Rhamnaceae). Balduinia, n. 14, p. 19-28, 2008.

SANTOS, S.R. Estudo anatômico do lenho e descrição morfológica de cinco espécies sul-riograndenses da família Rhamnaceae. Santa Maria: UFSM, 2008. 121 f. Dissertação (Mestrado em Engenharia Florestal - Universidade Federal de Santa Maria).

SHELL, R. Teoria e métodos em antracologia. Considerações teóricas e perspectivas. Arquivos do Museu Nacional, Rio de Janeiro, v. 62, n.1, p.314, 2004.

SILVA, J.G.; OLIVEIRA, A.S. A vegetação de restinga no município de Maricá, RJ. Acta Botanica Brasilica, São Paulo, v. 3, n. 2, p. 253272, 1989.

SOUZA, V.C.; LORENZI, H. Botânica sistemática: Guia ilustrado para identificação das famílias de fanerógamas nativas e exóticas no Brasil, baseado em APG II. Nova Odessa: Instituto Plantarum, 2008. p. 428-431.

TORTORELLI, L.A. Maderas y bosques argentinos. Buenos Aires: Orientación Gráfica Editora, 2009. v. 1. p. 509-513. 